\title{
Os saberes docentes e as práticas pedagógicas de Licenciandos em Informática: um estudo diagnóstico
}

\author{
The teaching knowledge and the pedagogical practices of Computer Future \\ Teachers: a diagnosis study
}

Francisco Ranulfo Freitas Martins Júnior

Universidade Estadual do Ceará (UECE)

Universidade Aberta do Brasil (UAB)

Rua José Hamilton de Oliveira, 160.

Polo Limoeiro do Norte - CE - Brasil

ranulfo.freitas@uece.br

\author{
José Ossian Gadelha de Lima \\ Faculdade de Educação de Crateús (FAEC) \\ Universidade Estadual do Ceará (UECE) \\ Rua José Saboia Livreiro, 1480 - Altamira \\ Crateús - CE - Brasil \\ jose.lima@uece.br
}

\begin{abstract}
Resumo A prática docente em Informática Educativa ainda é uma experiência recente no cenário brasileiro e, consequentemente, no cearense. Embora a Tecnologia avance num ritmo mais acelerado do que a Educação, esta última deve ser condicionada para agir como mola propulsora do desenvolvimento da estrutura social de uma nação. Neste sentido, o Brasil carece de um adequado tratamento no que diz respeito à Informática Educativa, para que estes dois setores progridam em harmonia. Fundamentado nessas conjecturas, o objetivo deste trabalho foi apresentar o resultado de uma investigação que buscou analisar e discutir a relação entre os saberes docentes tecnológicos e as práticas pedagógicas inovadoras em EaD. Esta pesquisa-ação foi desenvolvida junto a uma turma de dez Licenciandos em Informática da UECE/UAB. Para isso, esses sujeitos, participantes da pesquisa, desenvolveram atividades de regência por meio de um planejamento didático, considerando a práxis do professor de Informática. Eles puderam utilizar as TICs durante a realização de ações educativas em suas regências. Pela pesquisa, constatou-se que algumas necessidades formativas precisam ser melhor estudadas e discutidas. No entanto, elas só poderão ser supridas por meio de um planejamento didático colaborativo, que se fundamente nos parâmetros da abordagem andragógica utilizada na EaD. Com o advento desta modalidade de ensino, trazendo seus múltiplos recursos didáticos, atrelada a uma adequada formação inicial do professor, poderá se tornar possível uma remodelação elou uma ressignificação das ações constitutivas do processo educativo em Informática.
\end{abstract}

Palavras-Chave: Informática Educativa, Didática, EaD, Formação de Professores, Ensino de Informática.

\footnotetext{
Abstract The teaching practice in Educational Computing is still a recent experience in the Brazilian scenario and, therefore in Ceará. Although Technology advances at a faster pace than Education, this last one should be conditioned to act as driving force of the social structure of a nation's development. In this sense, Brazil lacks adequate treatment with regards to Educational Computing, in order to these two sectors to progress in harmony. Based on these conjectures, the aim of this work was to present the result of an investigation that aimed to analyze and discuss the relationship between technological teaching knowledge and innovative teaching practices in Distance Education. This action-research was developed with a group of ten Computer Future Teachers in UECE/UAB. To that end, the subjects, researchers participating, developed some didactic activities by means of a didactic planning, considering the practice of the Computer teacher. They could use ICTs for the realization of educational activities in their regencies. For the research, it was found that some training needs need to be better studied and dis-
} 
cussed. However, they will only be supplied by means of a collaborative didactic planning, that is founded on parameters of andragogical approach used in Distance Education. With the advent of this type of education, arrangements that brings multiple instructional resources, linked to an adequate initial training of teacher, It might become to make a renovation and a redefinition of the constituent stocks of the educational process in Computer.

Keywords: Education Computing, Teaching, e-Learning, Teacher Training, Computer Teaching. 


\section{Introdução}

Com o advento da era da informação, época marcada pela síntese, armazenamento, manipulação, decodificação e propagação, em larga escala, das mais diversas informações, dos variados campos do conhecimento (Social, Político, Econômico, Educacional, Científico, Tecnológico, entre outros), surgem novas demandas sociais. Tais demandas precisam ser resolvidas por resultarem de situações problematizadas que surgem no meio da prática social, sendo conflitantes por envolverem a informatização dos processos nos mais variados setores da estrutura social. Assim, essas situações inesperadas e inusitadas precisam de um adequado tratamento para que sejam respondidas [1].

Em tal contexto, a informatização substituiu os vários processos mecanizados que dominavam as diversas ações práticas cotidianas, inerentes ao desenvolvimento social. A capacitação humana para a utilização desses processos informatizados não acompanhou o ritmo acelerado de sua impactante implantação. No decorrer dessas situações descompassadas surgiu a Informática Educativa, que por meio do princípio da inclusão digital, contribui com as ações de educadores e educandos, possibilitando-os a aprendizagem de um pensar crítico-reflexivo para com situações problemáticas [2].

Tal cenário de inquietudes se encaixa bem com a descrição de Lévy [1] quando relata que a era da informação sintetiza instrumentos (tecnologias) que servem prioritariamente para valorizar a cultura, as competências, os recursos e os projetos locais, no intuito de engajar a população na participação de coletivos de ajuda mútua e em grupos de aprendizagem cooperativa.

Porém, por mais interessante e atrativa seja a utilização destas novas Tecnologias da Informação e Comunicação (TICs) no enfrentamento das atuais demandas, ela, por si só, não garante respostas aos problemas contextuais da região de sua aplicação. De acordo com o pensamento de Kenski [3], a utilização pedagógica destas tecnologias necessita de um tratamento didático a ser realizado pelo professor no exercício de sua práxis.

Corroborando com as ideias de Charlot [2], a formação inicial e/ou continuada do professor deve encaminhálo rumo ao desenvolvimento de uma prática pedagógica inovadora, e de uma utilização consciente de seus saberes docentes tecnológicos. Uma das etapas desta formação ocorre quando o Licenciando em Informática, professor em formação, cursa a disciplina de Didática Geral.

Franco e Pimenta [4] avaliam que a Didática, enquanto ramo de conhecimento da Educação, possibilita que os professores das áreas específicas, Informática no caso, pedagogizem as tecnologias, isto é, convertam-nas em matéria de ensino, colocando os parâmetros pedagógicos (da Teoria da Educação) e didáticos (da Teoria do Ensino) na docência desta disciplina, que possui raízes científicas. Articulam-se assim os parâmetros desenvolvidos em EaD (Educação a Distância) com os elementos lógico-específicos dos conhecimentos próprios da área de Informática, podendo ser configurado e compreendido o ramo da Didática da Informática.

Baseado nos pressupostos evidenciados até aqui, que podem trazer contribuições para a utilização das TICs na formação inicial do professor de Informática, o objetivo deste trabalho foi apresentar os resultados da análise e discussão sobre a relação entre os saberes docentes tecnológicos e as práticas pedagógicas inovadoras em $\mathrm{EaD}$.

Uma investigação para o alcance deste objetivo foi desenvolvida com alunos do quarto semestre do Curso de Licenciatura em Informática em EaD, que é mantido pela Universidade Estadual do Ceará (UECE) que possui convênio com a Universidade Aberta do Brasil (UAB), funcionando no polo de Limoeiro do Norte, município da região do Vale do Jaguaribe no Estado do Ceará.

Os sujeitos participantes desenvolveram atividades de regência por meio de um planejamento didático que considerou a práxis do professor de Informática. Eles puderam utilizar as TICs durante a realização de ações educativas em suas regências.

Justificou a realização desta pesquisa, a consideração do planejamento didático como um instrumento teóricoprático que subsidia o relacionamento entre os saberes docentes tecnológicos e as práticas pedagógicas. Este planejamento, utilizado como ferramenta pedagógica por estes Licenciandos durante a regência de uma aula de Informática, concebida e desenvolvida dentro dos parâmetros da EaD, norteou tal relacionamento. Sendo constituída como objeto desta pesquisa, esta regência foi uma das formas de avaliar o desempenho deles na disciplina de Didática Geral.

\subsection{Breve Histórico da Informática Educati- va no Ceará}

A Informática Educativa surgiu no cenário cearense como uma tentativa de suprir as carências da sociedade relativas aos conhecimentos tecnológicos. Isto foi resultante da introdução desses conhecimentos na educação brasileira. Moraes [5] atesta que, a partir de meados da década de 1970, o Brasil buscava autonomia no processo de informatização de seus setores estruturais, acreditando que este seria um passo decisivo na construção de uma base para uma capacitação nacional.

Observando o cenário da implementação da informática brasileira, Quirino [6] fala que o Estado do Ceará desenvolveu, nas décadas de 1980 e 1990, alguns projetos 
voltados para a cultura da informatização, um deles foi o EDUCOM (Educação e Computador) que resultou na criação do Centro de Informática Educativa (CIED). Após a criação destes projetos, o Governo do Estado do Ceará desmembrou a Secretaria de Educação, Cultura e Desporto (SECD) em duas distintas, a Secretaria de Educação (SEDUC) e a Secretaria de Ciência e Tecnologia (SECITECE). Este desmembramento possibilitou a criação do Núcleo Tecnológico do Ceará (NUTEC) e do Instituto do Software do Ceará (INSOFT), além da Fundação Cearense de Apoio ao Desenvolvimento Científico e Tecnológico (FUNCAP). Em 1996, a partir de uma parceria estabelecida entre SEDUC e SECITECE, foi instalado no Estado o Fórum de Informática Educativa (INFOEDUCAR).

Este panorama recaiu sobre a UECE, que foi pioneira em ofertar, nas décadas de 1990 e início dos anos 2000, cursos em EaD para o estado. As ações educativas desta nova modalidade foram executadas graças ao Núcleo de Educação Continuada e a Distância (NECAD), do Centro de Educação da referida universidade [7].

Vidal e Maia [8] contextualizam a implementação da EaD pela UECE relatando que, em 2005, a Reitoria desta instituição criou a Secretaria de Educação a Distância (SEAD), regulamentada por meio da Resolução $\mathrm{n}^{0}$ 355/CD de 09/05/2008. Destacam-se entre os principais objetivos da SEAD: a) sistematizar e propor em conjunto com os Centros, Faculdades e Pró-Reitorias políticas de projetos e ações em $\mathrm{EaD}$ a serem realizadas pela UECE; b) coordenar os projetos e ações em EaD na UECE nas áreas de ensino, pesquisa e extensão; c) operar uma plataforma única de $\mathrm{EaD}$ para a UECE.

Em 2006, por meio do Edital de Seleção UAB n ${ }^{\circ}$ 01/2006-SEED/MEC/2006/2007, o MEC propôs a institucionalização de alguns cursos de Licenciatura [9]. Para esta seleção a UECE apresentou a proposta para a criação de sete cursos em EaD: Física, Química, Ciências Biológicas, Matemática, Pedagogia, Informática e Artes Plásticas. Todos foram aprovados e iniciaram suas atividades em 2009.

No ano de 2012 foram iniciadas as atividades do curso de Licenciatura em Informática (polo de Limoeiro do Norte) da UECE/UAB. Segundo a Secretaria de Apoio às Tecnologias Educacionais (SATE) da UECE [10], o objetivo central desse curso é: propiciar uma formação sólida e abrangente de educadores, com base nas áreas de Computação e técnicas de Informática, enfatizando aspectos científicos, técnicos, pedagógicos e sociais.

Vidal e Maia [8] afirmam que o curso de Licenciatura em Informática da UECE/UAB destina-se a estimular a geração de inovações no processo da formação de educadores para a educação básica, preparando-os para o exercício do magistério suportado por tecnologias de Infor- mática e fundamentos de Computação.

\subsection{Sistemática do Funcionamento da EaD na UECE}

A sistemática do funcionamento da EaD na UECE se baseia na inserção das TICs no processo de ensinoaprendizagem, visando o crescente grau de interatividade. Tal fato pode permitir a alteração das restrições de tempo e espaço, tão marcantes no ensino tradicional. Neste enfoque, Graham [11] diz que há uma aproximação entre a realidade real e a virtual, quando ações educacionais são desenvolvidas.

A Figura 1, adaptada para o contexto desta aproximação, demonstra o desenvolvimento dos sistemas de Aprendizagem Virtual Interativa (AVI) e a convergência com a Aprendizagem Presencial (AP), o que gera o Blended Learning $(B L)$.

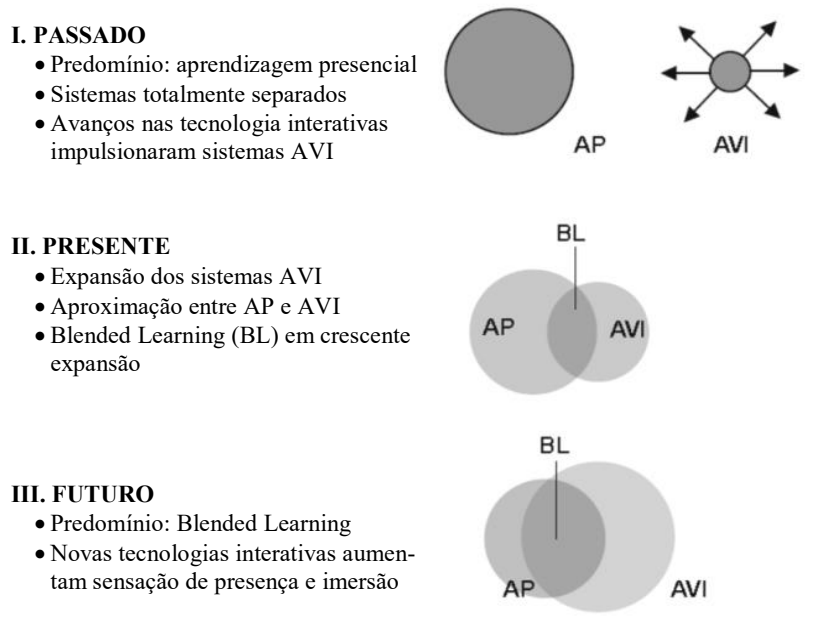

Figura 1: Evolução dos sistemas de Educação Presencial e a Distância. Adaptada de Graham [11].

Pelo modelo de evolução de Graham [11], fica entendido que o $B L$ é uma mescla interativa das aprendizagens presencial e virtual. Na modalidade de Educação Presencial há uma limitação do uso de metodologias de ensino, pois de forma prática, só é possível utilizar uma de cada vez, em detrimento de sua dinâmica de atividades estar restrita a fatores como espaço e tempo.

Em contrapartida, as ideias de Kenski [3] para a EaD estão fundamentadas no uso simultâneo de variadas metodologias de ensino, que aumenta a interatividade entre os atores do processo de ensino-aprendizagem: professoraluno, aluno-professor, aluno-aluno, aluno-tecnologia, tecnologia-aluno.

O eventual crescimento da EaD no cenário brasileiro e, consequentemente, no cearense, para Vidal e Maia [8], é resultante do respeito de tal modalidade ao ritmo de desenvolvimento cognitivo do aluno, ou seja, a conside- 
ração da evolução de sua aprendizagem. Isto contribui com o ativismo e produtividade do educando.

Esses mesmos autores atestam que a EaD tenta alcançar um estágio de equilíbrio entre o desenvolvimento da aprendizagem autônoma e as atividades interativas dos alunos. Assim, ao ser elaborado o planejamento didático para as ações educativas, é necessária observância e respeito as peculiaridades de cada mídia, para que contribuam com uma efetiva prática didático-tecnológica.

As diretrizes do Curso de Licenciatura em Informática da UECE/UAB estão norteadas pelo princípio do modelo andragógico, que na visão de Martins [12], está baseado na capacidade do aprendiz em aprender, independente da faixa etária que ele esteja incluso. $\mathrm{O}$ termo andragogia (do grego andros - adulto e - agogus - guiar, conduzir, educar), utilizado pela primeira vez em 1833 , se refere à Teoria da Educação de Platão, pois seus postulados inferem ao exercício da indagação, da interação e da dialética com grupos de jovens e adultos.

Knowles [13] esclarece que o modelo andragógico se baseia em quatro pilares: a) a posição do aprender varia de uma condição de dependência para independência através do desenvolvimento autônomo; b) a síntese de experiências de aprendizagem, que podem ser utilizadas no processo de construção de conhecimento; c) a prontidão em aprender está associada a prática social; d) as perspectivas de tempo e de currículo mudam de adiamento para o imediatismo pela aplicação do que é aprendido, priorizando, com isto, o desempenho.

$\mathrm{O}$ modelo andragógico de aprendizagem utilizado em EaD na UECE/UAB, segundo as proposições de Vidal e Maia [8], também se baseia na experiência educativa de Dewey, na construção de conhecimento de Piaget, na interação social de Vygotsky e na educação transformadora de Paulo Freire.

Na concepção de Dewey [14] a experiência não é sintetizada pela transmissão de informações como sendo produtos finais, prontos e acabados. Ele expressa que as informações proferidas no ensino não podem ser consideradas como verdades absolutas, isentas de reflexão, criticidade e significado para o aluno. Na realidade, a incorporação de informações adquiridas na vida cotidiana do cidadão-aluno deve fazer relação com as que estão sendo propostas no ensino.

As concepções de Piaget e Vygotsky [15] para aprendizagem interativa são definidas na construção da inteligência a partir das relações recíprocas que ocorrem entre o homem e o meio. Para Piaget, o individuo processa uma forma individual de conhecimento por meio da organização interna de experiências que posteriormente se adaptarão ao meio. Para Vygotsky, o indivíduo internaliza o conhecimento repassado pelos mais experientes, num processo de transmissão de cultura.

Paulo Freire [16] expressa em sua obra "Pedagogia da autonomia" o termo autonomia como sendo algo que naturalmente é construído pela experiência de cada ação e atitude tomada. Para ele:

(...) a autonomia, enquanto amadurecimento do ser para si, é processo, é vir a ser. Não ocorre em data marcada. É neste sentido que uma pedagogia da autonomia tem de estar centrada em experiências estimuladoras de decisão e da responsabilidade, vale dizer, em experiência respeitosas da liberdade [16, $p$. 107].

Percebe-se que estas quatro concepções de aprendizagem estabelecem uma aproximação intrínseca entre o modelo Andragógico e o Pedagógico. Tal fato pode ser observado logo abaixo.

\begin{tabular}{|c|c|c|}
\hline \multicolumn{3}{|c|}{$\begin{array}{c}\text { COMPARATIVO ENTRE } \\
\text { OS MODELOS PEDAGÓGICO E ANDRAGÓGICO }\end{array}$} \\
\hline & Modelo Pedagógico & Modelo Andragógico \\
\hline $\begin{array}{c}\text { Papel da } \\
\text { Experiência }\end{array}$ & $\begin{array}{c}\text { A experiência daquele que } \\
\text { aprende é considerada de pouca } \\
\text { utilidade. O que é importante, } \\
\text { pelo contrário, é a experiência } \\
\text { do professor. }\end{array}$ & $\begin{array}{l}\text { Os adultos são portadores de } \\
\text { uma experiência que os distin- } \\
\text { gue das crianças e dos jovens. } \\
\text { Em numerosas situações de } \\
\text { formação, são os próprios } \\
\text { adultos com a sua experiência } \\
\text { que constituem o recurso mais } \\
\text { rico para as suas próprias } \\
\text { aprendizagens. }\end{array}$ \\
\hline $\begin{array}{l}\text { Vontade de } \\
\text { aprender }\end{array}$ & $\begin{array}{l}\text { A disposição para a prender } \\
\text { aquilo que o professor ensina } \\
\text { tem como fundamento critérios } \\
\text { e objetivos internos à lógica } \\
\text { escolar, ou seja, a finalidade de } \\
\text { obter êxito e progredir em } \\
\text { termos escolares. }\end{array}$ & $\begin{array}{l}\text { Os adultos estão dispostos a } \\
\text { iniciar um processo de aprendi- } \\
\text { zagem desde que compreendam } \\
\text { a sua utilidade para melhor } \\
\text { enfrentar problemas reais da sua } \\
\text { vida pessoal e profissional. }\end{array}$ \\
\hline $\begin{array}{l}\text { Orientação da } \\
\text { Aprendizagem }\end{array}$ & $\begin{array}{l}\text { A aprendizagem é encarada } \\
\text { como um processo de conheci- } \\
\text { mento sobre um determinado } \\
\text { tema. Isto significa que é } \\
\text { dominante a lógica centrada nos } \\
\text { conteúdos, e não nos problemas. }\end{array}$ & $\begin{array}{l}\text { Nos adultos a aprendizagem é } \\
\text { orientada para a resolução de } \\
\text { problemas e tarefas com que se } \\
\text { confrontam na sua vida cotidia- } \\
\text { na (o que desaconselha uma } \\
\text { lógica centrada nos conteúdos). }\end{array}$ \\
\hline Motivação & $\begin{array}{l}\text { A motivação para a aprendiza- } \\
\text { gem é fundamentalmente } \\
\text { resultado de estímulos externos } \\
\text { ao sujeito, como é o caso das } \\
\text { classificações escolares e das } \\
\text { apreciações do professor. }\end{array}$ & $\begin{array}{l}\text { Os adultos são sensíveis a } \\
\text { estímulos da natureza externa } \\
\text { (notas, etc.), mas são os fatores } \\
\text { de ordem interna que motivam o } \\
\text { adulto para a aprendizagem } \\
\text { (satisfação, autoestima, qualida- } \\
\text { de de vida, etc.). }\end{array}$ \\
\hline
\end{tabular}

Quadro 1: Comparativo entre os modelos Pedagógico e Andragógico. Fonte: Goecks, 2003.

\subsection{O Planejamento Didático em EaD}

Almeida e colaboradores [17] afirmam que a Didática passou de um modelo ideal de parâmetros que tentavam regular a postura do professor em sala de aula, para um conjunto de saberes docentes e práticas pedagógicas que respaldam o professor para tomar decisões que facilitam a construção de experiências de aprendizagens de seus alunos. 
Refletir criticamente a Didática contemporânea, com suas atribuições à $\mathrm{EaD}$, poderá permitir, principalmente as instituições de fomento formativo, o seu relacionamento à formação docente. Silva e Navarro [18] atrelam este relacionamento ao próprio contexto histórico da evolução desta disciplina, indicando com isto a importância de seus conhecimentos ao papel no fazer do professor.

Entendida a Didática como conhecimento que respalda a atuação pedagógica, o planejamento dela, enquanto atividade do professor, é tarefa primordial, sobretudo quando estar inserida ao modelo andragógico.

Sobre o exposto, ressaltam-se contribuições de estudiosos do assunto.

\subsubsection{Função do Planejamento}

Gandin [19] concebe o planejamento como uma ação política de caráter decisório, para que o professor use sua autonomia nas decisões relativas ao fazer docente. Assim, o planejamento norteará as ações educativas para a promoção de aprendizagem.

Padilha [20] destaca que a autonomia do professor potencializa o ato de planejar, aproximando esta atividade do Projeto Político Pedagógico (PPP) de sua instituição de ensino. No entanto, para tornar isso possível, é necessário que ele, durante a formação inicial, faça uso da criatividade na busca de um caminho a ser trilhado, norteando-o com metodologias adequadas que minimizem o desencontro com o destino final almejado no planejamento.

\subsubsection{As Características da Prática do Plane- jamento}

A flexibilidade e a participação coletiva são itens que necessitam ser observados na prática do planejamento, principalmente quando é pretendida a mobilização de toda uma instituição de ensino [21].

Almeida [22] diz que o planejamento precisa ser apresentado como um produto sintetizado a partir de um processo coletivo decorrente da construção de ideias e práticas pedagógicas. Silva [23] alega que é importante que o planejamento seja coerente, para que os diferentes objetos que o constituem (conteúdo, objetivos, recursos didáticos, metodologia, avaliação, entre outros) apresentem uma relação lógica e recíproca com os elementos constitutivos da escola (PPP, plano de desenvolvimento da escola e o próprio regimento escolar).

\subsubsection{O Início do Planejamento}

Briza [24] diz que o planejamento não se inicia nem tampouco se esgota na elaboração de planos, mas deve estar centrado no diagnóstico da realidade sobre a qual se pretende agir, interferir, adaptar e alterar. Este dimensio- namento permite o estabelecimento dos parâmetros constituintes do planejamento, ou seja, os objetivos a serem alcançados com o trabalho empreendido; os conteúdos ou as temáticas a serem exploradas; as ações educativas de aprendizagem e ensino a serem vivenciadas; os recursos didáticos que viabilizem o progresso do planejamento; e, por fim, a sistemática de avaliação da aprendizagem.

\subsubsection{Os Atores do Planejamento}

Libâneo [25] mostra a importância de se evitar a prática de um planejamento fragmentado, numa situação discrepante entre os que decidem e impõem como deve ser o planejamento (supervisores, coordenadores e professores), e os que seguem-no e agem frente o que ficou previamente decidido (alunos). Para ele, as ações educativas contidas nesse instrumental devem ser desenvolvidas coletivamente entre os partícipes. Pelo olhar deste estudioso, é possível inferir que, a Informática Educativa, usada no ambiente da sala de aula, estimula o professor a se tornar um agente educacional que contribui com a formação do aprendiz, enquanto este último, ao influenciar na elaboração do planejamento, corrobora com a mediação didática do professor.

Por esses motivos, o planejamento necessita fazer parte da ação didática no âmbito educacional. Neste ponto, Damis [26] esclarece que planejar é uma prática sóciopolítica estabelecida não somente como instrumento organizador do trabalho pedagógico, mas também como um elemento de autoformação pessoal e profissional.

\subsubsection{Partes do Planejamento Pedagógico}

Objetivos: estão referenciados na lógica de tempo e de espaço, sendo determinados na abordagem tanto dos aspectos cognitivos, quanto dos aspectos relacionados à formação de valores capazes de sintetizar experiências subjetivas de aprendizagem e prática docente [27]. Estes objetivos precisam ser negociados democraticamente pelos profissionais que atuam nas instituições educacionais, para que sejam incorporados como práticas pedagógicas.

Conteúdos: para que os saberes acadêmicos e escolares sejam trabalhados de forma pedagógica, Castro e Tucunduva [28] falam que a organização curricular deve levar em consideração a gradação das dificuldades conceituais, a necessidade de prosseguimento, bem como a continuidade nos estudos para o aprofundamento dos princípios trabalhados nos conteúdos. Dessa maneira são aumentadas as possibilidades de aquisição de uma saber contextual e interdisciplinar que relacione, de forma essencial, a Ciência com a Tecnologia.

Metodologia: princípio que norteia o fazer docente como práxis direcionada à aprendizagem. Segundo Moran [29], a metodologia deve se constituir em um ato 
coletivo promotor do processo de conversão da informação em conhecimento. Assim, há uma transformação da prática pedagógica do professor em ação didática, processo que poderá facilitar a evolução das concepções prévias dos alunos para processos investigativos de descoberta, de interatividade e de livre expressão.

Recursos Didáticos: estes instrumentais da ação pedagógica do professor devem possuir a capacidade de criar situações que provoquem desafios e oportunidades de aprofundamento epistemológico, que se contrapõem as verdades absolutas transmitidas massivamente em um modelo de ensino tradicional [24].

Avaliação: surge da necessidade de estabelecer posicionamento de critérios, instrumentos e da própria periodicidade avaliativa. Estabelecer critérios avaliativos é exigir clareza aos objetivos a serem alcançados pelos alunos, para que seja apontado o que realmente precisa ser avaliado. Tais critérios referem-se aos conhecimentos, atitudes, destrezas, valores, reflexões, questionamentos, significados, atitudes e habilidades que deverão ser observados nos alunos submetidos ao processo avaliativo [30].

\section{Metodologia}

\subsection{Caracterização da Pesquisa}

A pesquisa realizada foi do tipo qualitativa. Fundamentado nas ideias de Terence e Filho [31], o trabalho desenvolvido buscou uma melhor compreensão do papel da formação inicial do professor, por meio da interpretação realizada nas próprias perspectivas didáticas dos Licenciandos em Informática da EaD.

Esta interpretação foi condicionada ao diagnóstico de alguns princípios didáticos: o planejamento pedagógico e seus elementos constituintes; a utilização das TICs, como o Ambiente Virtual de Aprendizagem (AVA) Moodle, na preparação das regências; o lecionar de regências; entre outras atividades inerentes a profissão do magistério.

Em termos de procedimentos técnicos, a investigação usada no trabalho foi a de uma pesquisa-ação do tipo diagnóstica [32], pois tanto o pesquisador, quanto os sujeitos investigados (Licenciandos) estiveram imbuídos dos pressupostos das atuais Teorias Educacionais, na tentativa de renovação e/ou ressignificação do ensino tradicional de Informática. A colaboração do trabalho coletivo buscou a implementação da Informática Educativa nas mais variadas ações didáticas da prática docente.

De acordo com Gil [33], a pesquisa-ação vem sendo gradativamente reconhecida como útil, sobretudo por pesquisadores que possuem uma ideologia "reformista" e "participativa".

\subsection{Campo da Pesquisa}

Este trabalho foi realizado no polo da UECE/UAB, em Limoeiro do Norte, município da região do Vale do Jaguaribe no Estado do Ceará.

Ele foi desenvolvido em uma turma de dez Licenciandos do Curso de Licenciatura em Informática, que no semestre 2014.1, cursaram a disciplina de Didática Geral, e, portanto, estavam estudando os principais pressupostos teóricos da prática docente. Com o decorrer deste percurso acadêmico, foi esperado, com a realização desta metodologia, um plausível relacionamento entre os saberes tecnológicos e as práticas pedagógicas inovadoras em EaD.

\subsection{Etapas da Pesquisa}

Fazendo uso dos conteúdos explorados nas aulas teóricas de Didática Geral, a pesquisa foi iniciada pelo estudo do instrumental teórico-prático acerca da ação docente. Dessa maneira, foram abordados conteúdos referentes aos seguintes temas: Fundamentos da Didática; Didática na Formação de Professores; Teorias Educacionais e a Docência; Identidade Profissional e a Didática; Planejamento da ação didática; e por fim, a expressão viva do Planejamento - a Aula.

A etapa seguinte foi realizada tendo em vista à supervisão do planejamento pedagógico dos Licenciandos, relativa a regência de uma aula que envolvesse uma temática na área de Informática Educativa. Eles tiveram autonomia para escolher livremente o tema da aula. Nesta escolha foram observados alguns critérios próprios da regência: título, objetivos, recursos didáticos, metodologias e avaliação. Para um melhor desenvolvimento das regências foi sugerido a eles que compartimentalizassem suas aulas em introdução, desenvolvimento e conclusão.

Esta etapa ocorreu na modalidade semipresencial, ou seja, em sala de aula, onde eram vistas as concepções preliminares do planejamento, e no Ambiente Virtual de Aprendizagem (AVA - plataforma da disciplina de Didática Geral) Moodle, quando ocorria a interação e a discussão telecolaborativa entre os Licenciandos. $\mathrm{O}$ objetivo desta etapa foi potencializar o desenvolvimento tanto do caráter individual (autônomo), quanto do caráter coletivo (cooperativo e/ou colaborativo) em cada um deles.

A terceira etapa foi a regência propriamente dita, ou seja, o lecionar da aula planejada. Antes de iniciar cada aula os Licenciandos entregavam ao pesquisador um plano de aula contendo todos os seus elementos constituintes (tema da aula, horário da aula, identificação do professor regente, objetivos, recursos didáticos, procedimentos metodológicos, avaliação e referências bibliográficas). As aulas foram lecionadas individualmente ou em equipe, conforme livre escolha deles. 
O objetivo desta etapa foi coletar os dados necessários para a realização da análise, discussão e reflexão, os quais se fundamentaram nas observações verificáveis, nos apontamentos coletivos, nas reflexões sobre as ações educativas desenvolvidas e nas críticas construtivas ao aperfeiçoamento docente.

\section{Resultados e Reflexões}

A seguir é apresentado um relatório sobre os resultados obtidos neste trabalho. Os resultados e as reflexões suscitadas fazem referência à terceira etapa discriminada na metodologia.

\subsection{Licencianda 1}

Esta Licencianda desenvolveu uma regência baseada nos conteúdos de Portas Lógicas, recorrendo ao estudo dos seguintes circuitos básicos padronizados: E, OU, NÃO, NÃO-E, NÃO-OU, XOR, e de Tabela Verdade. A introdução da aula foi realizada mediante uma exposição oral acerca das principais ideias que permeiam a temática central. Essa estratégia teve por objetivo estimular a concentração e a participação dos que assistiam.

Na sequência foi reproduzido um vídeo complementando a explicação dos conteúdos trabalhados, seguido de algumas discussões com a plateia. No final ela disponibilizou uma lista de exercícios, cujos objetivos foram: identificar os conhecimentos apreendidos pelos seus colegas e promover uma revisão dos assuntos abordados.

\subsubsection{Algumas reflexões sobre esta regência}

A metodologia predominante nesta aula foi a exposição oral, estando baseada em situações problematizadas que necessitaram ser analisadas e solucionadas pelos alunos através das informações assimiladas. Em relação à esta metodologia, Krasilchik [34] explica que o uso de uma problemática contemporânea para legitimar o tema central da aula intensifica o processo de participação dos alunos, que buscam alternativas para resolução dos problemas propostos pelo expositor.

A Licencianda organizou satisfatoriamente no quadro branco os conceitos, as aplicações e os exemplos associados à exploração dos conteúdos. Ela ainda disponibilizou um tempo adequado para que os ouvintes respondessem as questões da lista de exercícios que foi proposta.

Ações educativas dessa natureza facilitam o acompanhamento cognitivo dos alunos à medida que se desenvolve a aula. Esta prática docente no ensino da Informática se faz necessária porque contribui com o processo autônomo de construção do conhecimento, estando, portanto, em conformidade com a concepção de Paulo Freire [16].
A Licencianda reproduziu de um vídeo explicativo acerca de Portas Lógicas e de Tabela Verdade. Essa foi uma estratégia didática que poderá ter contribuído com a apreensão dos conteúdos abordados. Charlot [2] afirma que durante a formação inicial o professor deve conceber e desenvolver sua identidade profissional de forma crítica e autônoma, por meio da síntese de saberes científicos/tecnológicos, e de práticas pedagógicas que se utilizem das atuais inovações técnico-cientificas.

\subsection{Licenciandos 2 e 3}

Estes Licenciandos optaram por ministrar a regência em dupla. Ela foi lecionada a partir da explicação sobre um projeto desenvolvido por eles em uma escola de Ensino Médio da rede Pública do município de Limoeiro do Norte. O título da aula foi: "Radio Escola como instrumento de ensino".

A aula teve por intuito mostrar a importância da atividade desenvolvida no projeto Rádio Escola como prática pedagógica inovadora, capaz de colaborar com a melhoria do processo de ensino e aprendizagem.

Para isto, foram apresentados os recursos didáticos tecnológicos utilizados na atividade Rádio Escola. Foi reconhecida a importância da contribuição das atividades deste projeto em diversas ações educacionais cotidianas, tais como: a leitura, a escrita, o trabalho com textos, formas de dicção e compreensão da mensagem.

\subsubsection{Algumas reflexões sobre esta regência}

A abordagem de um projeto se mostrou pertinente durante a regência realizada, principalmente por se tratar da área de Informática Educativa. De acordo com Cachapuz e colaboradores [35], a realização de discussões sobre o desenvolvimento de projetos durante as aulas, principalmente daqueles ligadas as áreas de Ciência e Tecnologia, contribui para a renovação e/ou a ressignificação do ensino das mesmas.

A discussão realizada sobre a atividade Rádio Escola se mostrou bastante significativa, pois envolveu uma aplicabilidade no contexto da realidade social da comunidade escolar na qual foi desenvolvida. Portanto, esse tipo de discussão se afinou categoricamente às metodologias que fazem uso de situações problematizadas na abordagem de conteúdos.

Para os Licenciandos, a utilização de um software de rádio como tecnologia educacional, a exemplo do Audacity e Zararadio, pode auxiliar o processo de interação presencial e virtual entre professor, aluno e tecnologia. Este diálogo, intermediado, está de acordo com $B L$ de Graham [11]. 


\subsection{Licenciando 4}

Este Licenciando ministrou uma regência tendo por título: "Jogos digitais de raciocínio lógico como ferramenta de ensino na disciplina de Matemática para o Ensino Fundamental". Durante o desenvolvimento da regência foi abordada a utilização de jogos de raciocínio como recursos didáticos para o aprendizado da matemática escolar.

No decurso da aula foi explanado a utilização das TICs como ferramentas didáticas que auxiliam a transmissão de conteúdos de maneira agradável e eficaz. O uso didático de jogos de raciocínio lógico no ensino pode fazer com que os aprendizes das séries iniciais sintam-se atraídos por assuntos considerados complexos, permitindo que desenvolvam processos de aprendizagem autônomos.

\subsubsection{Algumas reflexões sobre esta regência}

Dois aspectos relacionados a forma de exploração de conteúdos ficaram evidenciados nessa regência. $\mathrm{O}$ primeiro diz respeito à interdisciplinaridade, pois os pressupostos didáticos da aula lecionada perpassaram convenientemente entre conteúdos informáticos e matemáticos. O segundo se refere à contextualização, uma vez que o conhecimento abordado foi trabalhado a partir de situações problematizadas (dificuldade na aprendizagem infantil de Matemática) advindas da realidade socioeducativa de jovens aprendizes.

Silva [36] atesta que ensinar por meio de jogos é um caminho para o educador desenvolver aulas mais interessantes, descontraídas e dinâmicas. Isto permite com que o ensino compita em igualdade com os inúmeros recursos transmissores de informação, disponíveis ao aluno fora do ambiente formal de aprendizagem.

A regência evidenciou o processo de aprendizagem por interação, ou seja, o $B L$ de Graham [11], que incita o aprendiz a interagir com a tecnologia de forma não hierárquica, porém autônoma, colaborando com o desenvolvimento de um ensino cientifico e tecnológico interessante e inovador.

O ensino de Informática em consonância com o das Ciências e da Matemática faz medrar o raciocínio lógico, o que instiga as faculdades cognitivas a evoluírem harmoniosamente dentro de uma lógica livre de um estado de dependência e/ou sujeição.

\subsection{Licenciando 5}

A regência deste Licenciando teve por título: "Uso das TICs no estudo de Inglês Instrumental". Seu desenvolvimento procurou relacionar os princípios da Informática Educativa com o ensino da Língua Inglesa.
Usando TICs na regência (computador, data-show, internet, dispositivos móveis e o Ambiente Virtual de Aprendizagem Moodle), o Licenciando demonstrou que o Inglês ocupa lugar de destaque em relação à comunicação universal. Embora possam parecer aparentemente distintas, Informática e Língua Inglesa oferecem recursos acessíveis à operacionalização de habilidades básicas da linguagem e da dialogicidade, tais como: ouvir, falar, ler e escrever.

Ele apresentou a importância do Inglês Instrumental no contexto social vigente, demonstrando a necessidade de capacitação para a compreensão de textos redigidos nessa língua. De uma forma prática, foram apresentadas algumas técnicas de leitura. As técnicas estavam fundamentadas no princípio do entendimento da ideia central do texto, que pode ser alcançado pela interpretação da leitura do título, das palavras-chaves e dos vocábulos expostos.

\subsubsection{Algumas reflexões sobre esta regência}

Um dos princípios que regem a Informática Educativa é a interação entre docentes, discentes e tecnologias por meio do uso didático da linguagem e da dialogicidade, independente da epistemologia da língua utilizada neste processo.

Segundo Moraes e Marques [37], é preciso incentivar e melhorar o uso das tecnologias digitais no ensino, principalmente entre os pesquisadores brasileiros que necessitam fazer uso da Língua Inglesa. Estes estudiosos esclarecem que a partir do ano 2000 o Inglês Instrumental começou a incorporar recursos da mídia virtual em sua abordagem. A utilização de TICs nos cursos e projetos de Inglês Instrumental tem sido objeto de muitas publicações em congressos, encontros, seminários e simpósios da área de Informática Educativa, realizados em várias Instituições de Ensino Superior brasileiras, inclusive as que fornecem $\mathrm{EaD}$.

A aplicação da Informática no ensino de Inglês Instrumental é uma estratégia contemporânea, atraente e passível de aplicação em cursos dessa língua. Esta prática também pode contribuir com o crescimento e fortalecimento do ensino de Informática.

\subsection{Licenciando 6}

Este Licenciando lecionou a regência: "Java como objeto de aprendizagem". Para ele, a linguagem Java, embora complexa, é passível de utilização na montagem de aplicações com acesso a bancos de dados em plataforma desktop, em dispositivos móveis, além de outras.

$\mathrm{O}$ foco da aula foi o uso orientado dessa linguagem como objeto de aprendizagem em Informática. A medida que a regência era desenvolvida, foi possível perceber que, além da Java, existem inúmeras técnicas de progra- 
mação orientadas para a síntese de objetos empregados no desenvolvimentos dos mais diferenciados softwares.

Ele realizou uma explanação teórica que ressaltou o relacionamento harmonioso entre alguns saberes de Informática com os de outras áreas do conhecimento. Para exemplificar esta relação, ele informou que: a Filosofia utiliza a lógica Aristotélica, abstração, eficiência e eficácia; a Matemática utiliza a lógica do raciocínio (proposições lógicas, tabelas verdade e álgebra de Boole), situações problematizadas, expressões matemáticas, conjuntos, funções, substituição de variáveis em equações, constantes, sequência, finitude e matrizes; e, por fim, a Língua Portuguesa utiliza a leitura e a interpretação de textos.

\subsubsection{Algumas reflexões sobre esta regência}

Apesar de ter como foco o uso da linguagem Java, a metodologia da aula esteve centrada na oralidade expositiva. No decorrer da regência não foi utilizado nenhum recurso didático, além do pincel e do quadro branco, que pudesse auxiliar a abordagem da temática proposta.

Os tópicos da aula foram dispostos no quadro branco sem uma adequada organização didática. Isto poderá ter dificultado a compreensão dos conteúdos transmitidos. Uma possível alternativa para sanar esta dificuldade poderia se constituir no uso didático de um fluxograma, e/ou de um mapa conceitual que favorecesse a evolução das concepções dos estudantes a partir do relacionamento com as que estavam sendo apreendidas [39].

Pinho, Greco e Schild [38] mostram que o ensino tradicional apresenta como vantagem o fato do professor centralizar o processo de abordagem dos conteúdos, isto pode acarretar num melhor controle de suas aulas. Contudo, esses mesmos estudiosos dizem que o ensino tradicional tende a dificultar a associação da teoria exposta com o cotidiano. Assim é agravado o problema de um ensino não significativo para a aprendizagem dos alunos.

Ausubel, Novak e Hanesian [39] são enfáticos em dizer que, o que está sendo proposto pelo professor, como objeto de aprendizagem, deve ser colocado a partir de um levantamento prévio das concepções cognitivas dos alunos. Para esses estudiosos é possível aprender a partir daquilo que já se conhece, por intermédio da reconfiguração das ideias já existentes nas funções mentais de cada aprendiz. Nessa situação o aprender ocorre a partir do que já está implantado na estrutura cognitiva.

Apesar de usar uma metodologia centralizada na oralidade, o Licenciando predominantemente apresentou um caráter interdisciplinar entre a Informática Educativa e outras áreas do conhecimento, tais como: a Filosofia, a Matemática e a Língua Portuguesa.

\subsection{Licenciando 7}

Este Licenciando lecionou a regência: "Lógica e linguagens de programação". Para ele, o objetivo da regência foi promover uma compreensão nos alunos acerca do conteúdo de Algoritmo Computacional. Foi feita uma explanação teórica das semelhanças entre sequências lógicas, uma usada para a realização de atividades do cotidiano, outra para a realização de atividades relacionadas ao conteúdo de Lógica de Programação.

Foi realizada uma introdução sobre este conteúdo através de uma breve comparação entre as sintaxes de algumas linguagens (Portugol, PHP e Java) no exercício de atividades diferenciadas para o ensino de Informática.

Ele concluiu sua regência informando que a aprendizagem de Informática pode ocorrer adequadamente, se mediada pela intervenção pedagógica do professor. Para ele, este fato reside no estudo das condições básicas necessárias à compreensão das semelhanças entre uma sequência lógica para a realização de atividades no contexto social, e também na realização de atividades relacionadas à Lógica de Programação.

\subsubsection{Algumas reflexões sobre esta regência}

Utilizar sequências lógicas como TICs em atividades rotineiras permite que o ensino de Informática seja contextual ao entorno social do aluno. Neste sentido, Valente [40] atesta que as TICs devem ser engajadas como ferramentas que auxiliem e dinamizem ações educativas contemporâneas. Tal engajamento poderá resultar em modificações significativas no processo de ensino e aprendizagem.

Valente continua, tornar o ensino de Informática contextualizado para a promoção de educação, provavelmente fará com que a sala de aula deixe de ser um lugar de cadeiras enfileiradas, tornando-se um ambiente de trabalho cooperativo e/ou colaborativo diversificado em níveis e interesses. Esse ambiente disponibilizará condições para a evolução social e cognitiva do aluno, de modo que ele aprenda a resolver problemas que surgem de forma inusitada e inesperada no seu cotidiano.

Neste novo ambiente é necessário que haja uma gama de atividades que propiciem o favorecimento do processo de construção de conhecimentos através de intervenções críticas e reflexivas do professor.

\subsection{Licenciandas 8 e 9}

Assim como os Licenciandos 2 e 3, estas optaram por ministrar a regência em dupla. O título da aula lecionada foi: "Avaliação da aprendizagem como prática pedagógica". 
Elas iniciaram explorando alguns pontos relativos ao processo de avaliação escolar, o que provocou profundas reflexões por parte daqueles que as assistiam. Elas buscaram ampliar o entendimento acerca da avaliação como um mecanismo constante de retroalimentação, cujo objetivo é melhorar o processo de construção ativa do conhecimento. $\mathrm{Na}$ exposição ficou claro que, os alunos, os professores e os demais agentes ligados a educação precisam adquirir a sensibilidade para enxergar a ligação intrínseca da avaliação com a aprendizagem. Nesta conjectura as TICs precisam ser integradas como recursos avaliativos do processo educativo, o que contribuirá com a aplicabilidade da Informática no ensinar e aprender.

De uma forma prática, elas utilizaram alguns softwares (Quiz, testes, questionários e desafios) passíveis de aplicação em educação, ao realizarem uma avaliação processual e dinâmica com o uso da internet. Elas demonstraram que o processo avaliativo deve ocorrer em três diferentes momentos do ensinar: I) antes da intervenção pedagógica (avaliação inicial); II) durante a intervenção pedagógica (avaliação processual) e III) depois da intervenção pedagógica (avaliação somativa).

\subsubsection{Algumas reflexões sobre esta regência}

Esta regência teve por objetivo discutir a prática avaliativa executada num processo de ensino e aprendizagem. Independente da área do conhecimento (Informática, Língua Estrangeira, Filosofia, Português, Química, Matemática, ou qualquer outra), o saber avaliar constituise como uma das necessidades formativas indispensáveis ao professor.

O pensamento analítico das Licenciandas, exposto anteriormente, comunga com Luckesi [41], quando ele afirma que as mais variadas ações educativas, a ser desempenhadas pelo professor, necessitam ser refletidas. Por isso é importante o processo auto avaliativo, que poderá contribuir com a experiência da prática docente.

Luckesi afirma que a avaliação necessita ser concebida e utilizada como um instrumental de aprendizagem que permite um feedback dos conhecimentos adquiridos ao longo do processo educacional. Assim, o professor não restringirá o conceito de avaliação para o de diagnóstico de saberes. Assumindo o papel de formador de pesquisadores iniciantes, este profissional deve se considerar corresponsável pelos resultados alcançados por seus alunos quando submetidos ao processo avaliativo.

Este saber docente ajudará na refutação de conceitos errôneos relativos a avaliação. A avaliação de um processo de aprendizagem significativa deve despertar nos alunos, professores e demais agentes educativos a capacidade de ressignificação deste instrumental, tornando possível a potencialização de saberes, destrezas, atitudes, reflexões e investigações educativas a partir de seu uso.

\subsection{Licencianda 10}

Esta Licencianda ministrou uma regência intitulada de: "Introdução a EaD". Os objetivos da aula foram: evidenciar e discutir os conceitos para esta modalidade educativa; e, apresentar o AVA Moodle como recurso didático acessível à operacionalização em EaD.

Observando estes objetivos, foram apresentados os tópicos mais relevantes da EaD. Algumas temáticas foram brevemente exploradas no sentido de ser delineado o histórico, a evolução e a disseminação dessa modalidade pelo Brasil e pelo mundo.

Fazendo uso da exposição teórica, ela relatou a importância da $\mathrm{EaD}$ na contemporaneidade, pretendendo minimizar algum preconceito que ainda possa existir acerca desta modalidade. Durante a regência foi informado que, atualmente o ensino a distância encontra-se em plena expansão no que se refere ao número de matrículas na Educação Superior do Brasil.

A regência foi concluída pelas reflexões: "educar e se educar a distância"; e "se há vontade em aprender, a EaD rompe com as barreiras de tempo e de espaço que trazem dificuldades aos aprendizes, legitimando o direito de se frequentar um curso de graduação, ou outro em qualquer modalidade".

\subsubsection{Algumas reflexões sobre esta regência}

As considerações da Licencianda são validadas por Vidal e Maia [8] quando relatam que, atualmente o papel do professor não pode ser restrito apenas a transmitir informações, pois a ele atualmente são requeridas múltiplas funções. Fica claro o redimensionamento que deve ser dado à prática docente, conferindo à esta atividade um profundo embasamento pedagógico capaz de promover uma aprendizagem que tenha significado.

\section{Para Vidal e Maia}

Todas essas mudanças no campo da informação, comunicação e conhecimento têm provocado desafios no plano da ação docente. As funções tradicionais dos professores têm sido questionadas em virtude da inclusão das tecnologias que chegam ao ambiente escolar. A sociedade do conhecimento do século XXI vem exigindo, cada vez mais, a melhoria dos padrões de qualidade na educação. Com isso demandam novas posturas profissionais daqueles que estão atuando em suas atividades laborais ( $p$. 107).

No ministrar dela ficou notória a importância da Informática Educativa tanto na modalidade da Educação Presencial, quanto em EaD. Vidal e Maia ressaltam a importância da UAB como instituição que surge no cenário nacional por iniciativa do Ministério da Educação 
(MEC), visando a inclusão social e educacional por meio da oferta de Educação Superior nos moldes do Ensino Semipresencial e a Distância.

\section{Considerações Finais}

A formação inicial do professor de Informática deve estar fundamentada nas necessidades formativas dele, que podem ser definidas como um conjunto de habilidades e competências que norteiam a prática docente, principalmente na tomada de decisões frente a situações inusitadas e inesperadas que advém do ensinar e aprender.

Pela pesquisa foram constatadas que algumas dessas necessidades formativas precisam ser melhor estudadas e discutidas, à saber: a) ensino por situações problematizadas que instiguem o diálogo; b) utilização pedagógica de recursos didáticos interativos; c) aproximação entre o ensino presencial e o virtual; d) abordagem de conteúdos científicos e tecnológicos que estimulem o desafio cognitivo; e) tornar interdisciplinar e contextual a linguagem Informática.

Graças ao estabelecimento de uma exequível associação entre o uso das tecnologias e os conhecimentos pedagógicos, será possível o surgimento e a aplicação de inovações didáticas que valorizem as experiências de aprendizagem, sintetizadas a partir da prática docente investigativa. Tal fato poderá contribuir com a superação de dificuldades inerentes ao ensino de Informática contemporâneo.

Para isto, o planejamento didático colaborativo se mostra como uma eficiente ferramenta pedagógica baseada nos parâmetros da abordagem andragógica da EaD. Cada Licenciando em Informática, participante dessa investigação, pôde desenvolver uma experiência subjetiva de aprendizagem no magistério. Essa experiência só se tornou significativa graças ao planejamento pedagógico, que teve por função contribuir com uma prática que possibilitou o desenvolvimento docente destes professores em formação.

Esta pesquisa buscou apresentar, através de exemplos de práticas docentes, como o professor de Informática pode relacionar seus saberes tecnológicos com suas práticas pedagógicas. Com o advento da EaD, que traz consigo múltiplos recursos didáticos, metodologias de ensino e necessidades formativas, surgem perspectivas para a remodelação e/ou a ressignificação das ações constitutivas do processo de ensino e aprendizagem em Informática.

Espera-se que a partir desta pesquisa surjam novos estudos em Informática Educativa que corroborem com a consolidação e potencialização deste ramo do conhecimento que se encontra em pleno desenvolvimento.

\section{Referências}

[1] P. Lévy. Cibercultura. Editora 34, São Paulo, 1999.

[2] B. Charlot. Da relação com o saber às práticas pedagógicas. Cortez, São Paulo, 2013.

[3] V. M. Kenski. Educação e tecnologias: o novo ritmo da informática. Papirus, Campinas, 2007.

[4] M. A. S. Franco, S. G. Pimenta (Orgs). Didática: embates contemporâneos. Loyola, São Paulo, 2010 .

[5] M. C. Moraes. Pontos de vista: o que pensam outros especialistas? Informática Educativa no Brasil: um pouco de história... Em Aberto, 12(57): 17-26, 1993.

[6] R. H. R. Quirino. O Projeto EDUCADI: a experiência na Escola de Ensino Fundamental Maria da conceição Porfírio Teles. In Anais do XV EPENN - Encontro de Pesquisa Educacional do Nordeste: Educação, Desenvolvimento Humano e Cidadania. São Luís, páginas 1-8, 2001.

[7] NECAD. Coordenação de educação continuada e a distância. Disponível em: http://www.ced.uece. Br/ index.php?option $=$ com_content\&view $=$ articl e\&id=70. Acesso em: 23 mai. 2015.

[8] E. M. Vidal, J. E. B. Maia. Introdução à educação a Distância. RDS Editora, Fortaleza, 2010.

[9] Ministério da Educação. Resultado do processo seletivo de pólos e cursos referentes ao edital 01/2006-CAPES/SEED/MEC. Disponível em: http://portal.mec.gov.br/seed/arquivos/pdf/UAB/ 126iário oficial republicacao4.pdf. Acesso em: 10 mai. $\overline{2} 015$.

[10] Secretaria de Apoio às Tecnologias Educacionais. Informática. Disponível em: http://www.uece.br/sate/ index.php/cursos/418informatica-nossos-cursos. Acesso em: 21 mai 2015.

[11] C. R, Graham. Blended learning systems: definition, current trends, and future directions. In $\mathrm{C}$. J. Bonk, C. R. Graham, J. Cross, M. G. Moore (Eds.) The handbook of blended learning: Global perspectives, local designs. Pfeiffer Publishing, São Francisco, páginas 3-21, 2006.

[12] R. M. K. Martins. Pedagogia e andragogia na construção da educação de jovens e adultos. Revista de Educação Popular, 12 (1): 143-153, 
2013.

[13] M. Knowles. The modern practice of adult education: andragogy versus pedagogy. Associated Press, New York, 1970.

[14] J. Dewey. The school and society. The child and the curriculum. University of Chicago Press, Chicago, 1990.

[15] A. O. Santos, G. S. de Oliveira, A. M. R. Junqueira. Relações entre aprendizagem e desenvolvimento em Piaget e Vygotsky: o construtivismo em questão. Revista Itinerarius Reflectionis, 10 (2): 1-31, 2014.

[16] P. Freire. Pedagogia da Autonomia. Paz e Terra, São Paulo, 1996.

[17] A. M. B. Almeida, J. R. Soares, J. O. C. B. Sales, M. M. S. C. Braga, M. M. D. Cavalcante, M. S. L. Lima. Didática Geral. RDS Editora, Fortaleza, 2010.

[18] O. G. da Silva, E. C. Navarro. A Relação professor-aluno no processo ensino-aprendizagem. Revista Eletrônica Interdisciplinar, 2 (8): 95100, 2012.

[19] D. Gandin. Planejamento como prática educativa. Loyola, São Paulo, 2010.

[20] P. R. Padilha. Planejamento dialógico: como construir o projeto político pedagógico da escola. Cortez, São Paulo, 2008.

[21] S. S. Colombo. Gestão educacional: uma nova visão. Artmed, Porto Alegre, 2004.

[22] A. M. B. Almeida. O plano de ensino: ponte entre o ideal e o real. In: A. M. B. de Almeida, M. S. Lucena, S. P. Silva (Orgs.). Dialogando com a escola. Demócrito Rocha, Fortaleza, páginas 53-61, 2002.

[23] S. P. Silva. Elementos constitutivos da identidade da escola. In: A. M. B. de Almeida, M. S. Lucena, S. P. Silva (Orgs.) Dialogando com a escola. Demócrito Rocha, Fortaleza, páginas 34-52, 2002.

[24] L. Briza. Proposta pedagógica e planejamento: as bases do sucesso escolar. Nova Escola, 181 (1): 26-29, 2005.

[25] J. C. Libâneo. Organização e gestão da escola: teoria e prática. Heccus, São Paulo, 2013.

[26] O. T. Damis. Planejamento escolar: expressão técnico-política de sociedade. In: I. P. A. Veiga. Didática: o ensino e suas relações. Papirus, Campinas, páginas 171-183, 2010.
[27] R. B. Leal. Planejamento de ensino: peculiaridades significativas. Revista Iberoamericana de Educación, 37 (3): 1-6, 2005.

[28] P. de Castro, C. C. Tucunduva; E. M. Arns. A importância do planejamento das aulas para organização do trabalho do professor em sua prática docente. Revista Cientrfica de Educação, 10 (10): 49-62, 2008.

[29] J. M. Moran. Novas tecnologias e mediação pedagógica. Papirus, Campinas, 2009.

[30] B. M. de F. Villas Boas. Portfólio, avaliação e trabalho pedagógico. Papirus, Campinas, 2005.

[31] A. C. F. Terence, E. E. Filho. Abordagem quantitativa, qualitativa e a utilização da pesquisaação nos estudos organizacionais. In Anais do XXVI Encontro Nacional de Engenharia de Produção. Páginas 1-9, 2006.

[32] B. T. Malheiros. Metodologia da pesquisa educacional. LTC, Rio de Janeiro, 2011.

[33] A. C. Gil. Como elaborar projetos de pesquisa. Atlas, São Paulo, 2006.

[34] M. Krasilchik. Práticas de Ensino de Biologia. Editora da USP, São Paulo, 2005.

[35] A. Cachapuz, D. Gil-Perez, A. M. P. de Carvalho, J. Praia, A. Vilches (Orgs.). A necessária renovação do ensino das ciências. Cortez, São Paulo, 2011.

[36] M. S. da Silva. Clube de matemática: jogos educativos. Papirus, Campinas, 2005.

[37] L. B. Moraes, T. M. F. Marques. Inglês instrumental - pressupostos teóricos e aplicabilidade. Revista Semente, 6 (6): 44-52, 2011.

[38] S. T. Pinho; P. J. Greco; J. F. G. Schild. Método situacional e sua influência no conhecimento tático processual de escolares. Motriz Revista de Educação Física, 16 (3): 580-590, 2010.

[39] D. P. Ausubel, J. D. Novak, H. Hanesian. Psicologia educacional. Interamenricana, Rio de Janeiro, 1980.

[40] J. A. Valente (Org.). O computador na sociedade do conhecimento. NIED/UNICAMP, Campinas, 1999.

[41] C. C. Luckesi. Avaliação da aprendizagem escolar. Cortez, São Paulo, 2011. 